\title{
The New Acropolis Museum on Twitter: Seven Years After
}

\author{
Ifigeneia Mylona*, Dimitrios Amanatidis
}

Department of Digital Media and Communication, Technological Educational Institute of Western Macedonia, Kastoria, Greece

Email address:

faymilona@yahoo.gr (I. Mylona),d.amanatidis@gmail.com (D. Amanatidis)

${ }^{*}$ Corresponding author

To cite this article:

Ifigeneia Mylona, Dimitrios Amanatidis. The New Acropolis Museum on Twitter: Seven Years After. Advances in Sciences and Humanities. Vol. 3, No. 5, 2017, pp. 61-72. doi: 10.11648/j.ash.20170305.14

Received: December 31, 2016; Accepted: January 12, 2017; Published: October 24, 2017

\begin{abstract}
Most museums around the world understand the importance of social media in order to promote their services, provide information to their future visitors, enable the communication interaction and create strong relationship with them. In this work we extract all tweets referring to the New Acropolis Museum in Greece. This spans the entire seven year time interval, from the first day that the specific account was created, up to the current day. We analyze the network of tweets and derive valuable information with respect to the engagement of users and discover other structural and conversational patterns that help us gain insight in this dialogue. A simple sentiment analysis reveals that the users hold a positive attitude towards the museum.
\end{abstract}

Keywords: Communication, Social Media, Twitter, NodeXL, Acropolis Museum

\section{Introduction}

Nowadays there is an increasing use of social media by individual users and organizations. The organizations use social media sites, including Twitter and Facebook to inform their users about events, to inform them about new products or services, but they also ask them to express their views about the organization, its events and products. The development of media and their impact on society have challenged cultural organizations like museums and provided them with new ways of communication and interaction with their public. The study focuses finding and analyzing all tweets related to the New Acropolis Museum; tweets were extracted with the use of NodeXL. The period of the research was from the 14th June 2009 till 23rd August 2016.

NodeXL (http://nodexl.codeplex.com/) is an application from the Social Media Research Foundation (http://smrfoundation.org/), which provides special support for social media data sources including Twitter, Facebook, YouTube, flickr, email, blogs, wikis, and the WWW. We have experimented with it in the past [1], by extracting and analyzing tweets containing some trending (at the time) hashtags. The period was immediately after the referendum outcome in Greece which initiated a pre-election period as well. As such, the tweets' network was quite time-sensitive and therefore not affected by the one-week limitation posed by the application.

The application's strength has been demonstrated in recent works, e.g.; in [2], fifty candidates for the 2014 US elections and respective political discussion in Twitter about them are considered and relational power gained is examined, in correlation with gender; in [3], the Starbucks \#RaceTogether campaign is studied, aiming to explore the central users in the discussion network and the factors contributing to a user's central status in the network; in [4], the South African, student-led campaign \#RhodesMustFall is in focus and a qualitative tweetcontent analysis enables the authors to claim that youth are increasingly using social media to engage in individualized activism, reflecting the politics and practices of counter-memory; and [5], where a library's Twitter network is analyzed and its impact visualized, arguing that social media managers can use such data to deliver relevant information and market services that will engage and benefit the library's online audience.

\section{Literature Review}

In this section, a review of related work is presented, focusing on Social Media and Twitter, and their use in 
museums. Some information is also given for the New Acropolis Museum.

\subsection{Social Media}

Scholars, advertisers and political activists, see online social networks as an opportunity to study and analyze them in order to examine how they are used by the organizations and institutions. Social media applications enable the collective creation and sharing of digital artifacts. The use of these tools inherently creates network data. These networks represent the connections between content creators as they view, reply, annotate or explicitly link to one another's content [6]. SNS are online services that allow users to create an individual profile, connect with other users - usually people known offline - and navigate through these networks of contacts [7].

Social media is a 21 st century term used to broadly define a variety of networked tools or technologies that emphasize the social aspects of the Internet as a channel for communication, collaboration, and creative expression, and is often interchangeable with the terms Web2.0 and social software [8]. From another point of view social media are "a group of Internet-based applications that build on the ideological and technological foundations of Web 2.0, which allow for the creation and exchange of user generated content" [9]. The characteristics of social media are; up-todateness, spontaneity and interactivity. The user is able to participate, to express his/her opinion. The most frequently used Web 2.0 applications include wikis (wikipedia.org), video sharing platforms (youtube.com), blogs (blogspot.com), and social networking sites (facebook.com, twitter.com).

Currently, Web 2.0 is the bandwagon everybody has to jump on. In the museum field, many institutions feel the pressure to join this trend but at the same time they are reluctant to do so because there is still a considerable lack of research about the acceptance of this new phenomenon both inside and outside the museum [10]. Most cultural institutions all over the world are using the Web 2.0 as they believe that this could be a good way for promoting their services and their facilities. Of course smaller arts institutions, in particular, are unable to hire additional staff to implement new projects such as social media [11].

\subsection{Twitter}

Twitter is an extremely popular online microblogging service, which has gained a very large user base, consisting of more than 105 million users (as of April 2010). The Twitter graph is a directed social network, where each user chooses to follow certain other users [12]. In order to give information to other users each user has to use tweets. Each user has a set of subscribers known as followers. Each user submits periodic status updates, known as tweets, which consist of short messages of maximum size 140 characters [13]. Recently however (on $16^{\text {th }}$ of September in 2016), Twitter has announced the relaxation of this limit, with a tweet stating that: “...photos, videos, GIFs, polls, and Quote Tweets no longer count toward your 140 characters". This effectively leaves more room for pure conversation (the tweet text) and was welcomed by users worldwide. Users declare the people they are interested in following, in which case they get notified when that person has posted a new message [14]. Twitter's importance is highlighted, e.g. in [15], who state that "...people use Twitter to communicate, to ask questions, to ask for directions, support, advice, and to validate open-ended interpretations or ideas by discussing with the others". Users declare the people they are interested in following, in which case they get notified when that person has posted a new message.

Each one can have a profile in Twitter. The profile can be public or private. The public profile includes the full name, the location, a web page, a short biography, and the number of tweets of the user [16]. Direct public posts are used when a user aims her update to a specific person and are signaled by a “@” symbol next to the person's username, whereas indirect updates are used when the update is meant for anyone that cares to read it [14].

Twitter seems to be an important social medium of collecting news. It promotes news discussion. It is also used for ongoing discussion for events. Twitter's "news coverage also consists of significant amounts of broader commentary on current events, reflecting mainly the sender's own perspectives and intended more as markers of those perspectives than as formal contributions to debate" [17].

Pew Research Center's Internet \& American Life Project conducted a research about the users of social media. In relation to Twitter the percentage of internet users who are on Twitter has doubled since November 2010, currently standing at $16 \%$. Those under 50 , and especially those $18-29$, are the most likely to use Twitter. Urban-dwellers are significantly more likely than both suburban and rural residents to be on Twitter. According to [18], over 200 million active Twitter users post 150 million tweets (messages) daily. At the third quarter of 2016, the microblogging service averaged at 317 million monthly active users [19].

Measuring influence in Twitter is a lengthy and complex task. Lengthy because it is an analysis that needs to account past actions of users, and complex because there is no precise consensus as to what influence is and how to measure it [20]. Twitter offers an Application Programming Interface (API) that is easy to crawl and collect data. NodeXL also supports extracting social network data from the Twitter microblogging and messaging service. Additional import connectors for social media sites are a direction for future work for the project [6].

\subsection{The New Acropolis Museum}

The New Acropolis Museum, officially inaugurated in June 2009 [21]. It is today the most visited of Greek museums [22]. It was designed by architects Bernard Tschumi and Michael Photiadis and opened to the public on $21^{\text {st }}$ June 2009, with Dimitrios Pandermalis as director of the project and the museum [23]. 
The museum is located on the pedestrian street Dionysiou Areopagitou, just 300 metres from the Acropolis, with the glass galleries of the upper floor providing visual contact to the Parthenon [24]. The visitor enters the museum in the spatial interval between the museum and the Acropolis Hill, unaware that this is the same interval that he or she will later be guided to look over, towards the Parthenon Temple [25].

The fact that a museum exhibition, wherever it may be, is not a static, unchanging matter is understood by most in the museum world [23]. As Jakobsen states [25], the "New Acropolis Museum in Athens clarifies the relevance of regarding the conditions of experience and events as part of a signaletic material that works through processes of differentiation and specification".

\subsection{Related Work}

Simon in [26], explored the ways that the philosophies of Web 2.0, which promote user participation and peer-to-peer interaction, can be applied in museums to encourage active discourse among visitors. She claimed that current web-based projects and potential in-gallery applications are explored, with a focus on networking individual visitor experiences as a basis for communal action.

Kidds in [27], publish a research about the use of social media in the museums sector in the UK and beyond. It seeks to explore the challenges of utilizing such media for institutions steeped in discourses of authority, authenticity and materiality. The findings of the research show that there is currently a gulf between the possibilities presented by social media, and their use by many museums. This leads to forms of frame misalignment, which can be intensely problematic. It is crucial that museums increase their understanding of the frames within which such activity is being encouraged and experienced.

In [28], a research is conducted about the use of Twitter in non-profit organizations. The study examines the Twitter utilization practices of the 100 largest nonprofit organizations in the United States. The analysis reveals there are three key functions of microblogging updates; "information", "community" and "action". Though the informational use of microblogging is extensive, nonprofit organizations are better at using Twitter to strategically engage their stakeholders via dialogic and community-building practices than they have been with traditional websites. Companies are not using Twitter to its full capacity as a stakeholder-engagement vehicle.

Hausmann in his study [11], examines how social media applications (social networks - especially Facebook, blogs and microblogs - like Twitter), are primarily used by German arts institutions in practice. Referring to NRW-Forum Dusseldorf and the use of Twitter from the museum the researcher claims that at the end of August 2011, the museum had 14,297 followers (plus 613 lists) and 2,336 tweets had been sent out. The content analysis of its tweets [29] during the four-week period revealed that the museum is impressively active on Twitter and posted 109 tweets (i.e. 3.5 tweets per day). In fact, the museum is the leader in the ranking of 111 German museums who use Twitter. Despite this fact though, the viral marketing effects are considered to be rather low.

Francesca De Gottardo, conducted a research [30] in order to examine how social media are used by the average smallmedium museum and what the attitude of the public is towards online museums. The research examined the online communication of 35 American museums. According to the research results, $100 \%$ of museums taken into consideration maintain a Facebook page but do not update it on a daily basis. $23 \%$ of museums do not have a Twitter profile as it is difficult for them to find a proper way to engage with followers on this platform. Instagram button is forgotten on most of websites. A significant part of museums has a Tripadvisor "Certificate of Excellence" on their website homepage.

Finally, another recent study was conducted by Badell in 2015 [31], to describe the current situation of Catalonian museums in social media. Results showed that only $60 \%$ of Catalan museums present a social media profile of their own, and most of them are significantly lacking feedback from their followers. Regarding the use of Twitter, the Picasso Museum stands out with the most followers (more than 40,100), followed by two other large institutions; the MACBA with 37,257 followers, and the MNAC with almost 33,400 followers. There are significant differences regarding interaction, which depends on the community manager and the communication policy of the museum. Some small or medium-sized centres are very active on Twitter and receive many replies.

\section{Methodology and Results}

In this section we present our methodology framework and our analysis findings, with some discussion taking place inline. As stated previously, the Twitter account of the New Acropolis Museum was created in June 2009 and has at the time of writing 2,367 followers.

\subsection{Methodology}

Our objective in this work was to extract all tweets related to the New Acropolis Museum and analyze the resulting network to identify key bloggers, as well as, structural and conversational patterns in this global engagement of communication on a specific topic.

There are several approaches in extracting the tweets, e.g. by accessing the Twitter API, or using a third-party, off-theshelf tool, such as NodeXL. However, there are some limitations when using the free versions of these tools. Usually, these are limitations with respect to the total number of tweets, or time limitations, hindering the extraction of tweets older than a week ago. So, we exploited Python as a means to circumvent this obstacle. We opted for "acropolismuseum" (case-insensitive) as the search string in the Twitter network API, thereby including both "@acropolismuseum" (and “.@acropolismuseum”) or "\#acropolismuseum" appearing anywhere in the text of the extracted tweets of interest. So all "replies", "mentions" or "hashtags" were considered and included in our sample.

The extracted tweets (2110 in total) were obtained in 
reverse chronological order (latest first) and exported in a.csv formatted file. The dates span from the time of extraction (23rd August 2016) to 14th June 2009, which was one week before the official museum opening day. This file had to undergo an additional preprocessing formatting stage, in order to be NodeXL-compatible. Several Excel functions were utilized in order that the data columns follow the format required by NodeXL. No other "data cleaning" process was performed at this stage and the processed data file was finally loaded into NodeXL for further analysis and visualization.

\subsection{Results}

Checking the summary of the network reveals some of its global features; there are 1403 vertices and 1225 unique edges. Moreover, a basic sentiment analysis done by NodeXL indicates that the conversation has a positive sign:

Table 1. Summary of the network.

\begin{tabular}{ll}
\hline Vertices & 1403 \\
Unique Edges & 1225 \\
Edges With Duplicates & 885 \\
Total Edges & 2110 \\
Self-Loops & 977 \\
Connected Components & 573 \\
Single-Vertex Connected Components & 467 \\
Maximum Vertices in a Connected Component & 693 \\
Maximum Edges in a Connected Component & 1308 \\
Maximum Geodesic Distance (Diameter) & 10 \\
Average Geodesic Distance & 3,507765 \\
Graph Density & 0,000916113 \\
\hline \multicolumn{2}{c}{ Twitter search $\quad$ Top Words in Tweet in Entire Graph: } \\
\multicolumn{2}{c}{ network top $\quad$ Words in Sentiment List $\$ 1:$ Positive } \\
\hline
\end{tabular}

Figure 1. Words in Sentiment List.

The first visualization of the network is shown below; clicking roughly at the centre of this "hairball" reveals that as expected all this is built around the "acropolismuseum" node (case sensitive - tooltip can help identify the node):

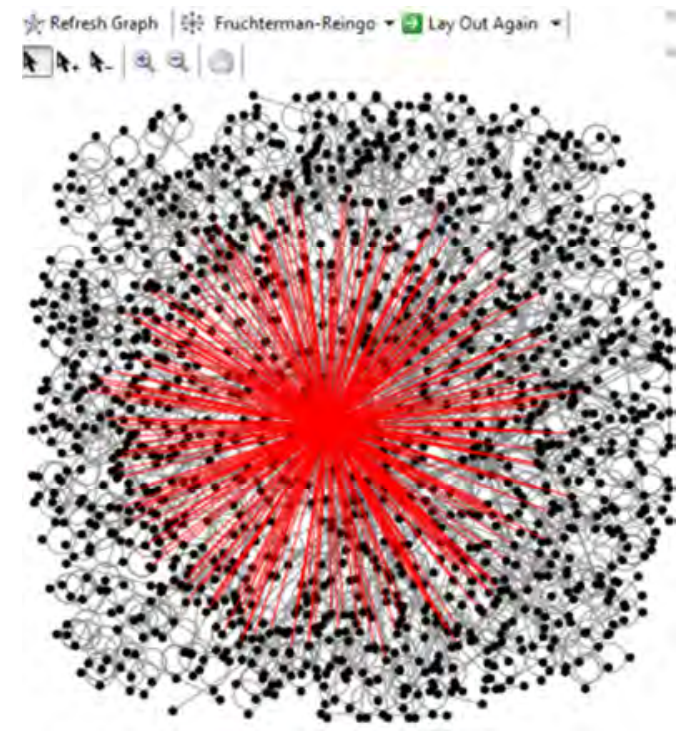

Figure 2. The initial visualization.
In the above figure, the records that are selected are edges categorized as "mentions" or "replies" and originate from any vertex to acropolismuseum as vertex 2 . At this point, we noticed that there are some inconsistencies included such as case differentiations, e.g. ACROPOLISMUSEUM, or "bad data", e.g. unintended blanks (acropolis museum) which results in the "acropolis" term appearing as a node or as a hashtag. So, we sorted our records according to vertex 2 and selected all (consecutive now) records with acropolismuseum as vertex 2 to get the network of incoming connections ("attention network"). The count of such records was 507. We also set the layout algorithm to Harel-Coren to better visualize the dominant cluster.

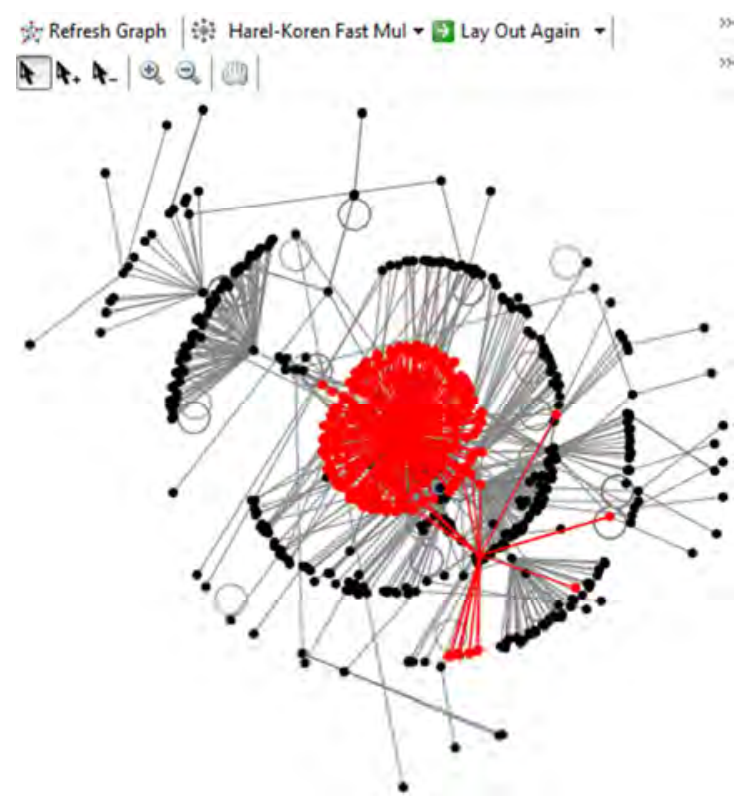

Figure 3. The ättention"network.

In doing so, we can see the formation of some clusters around the core of these 507 edges. We can also notice the existence of "brokers" or "bridges" for information flow between the clusters. In literature these are called "structural holes" or "weak ties" [32]. For example, the @Acropolis, @britishmuseum and (a)BCRPM (British Committee for the Reunification of the Parthenon Marbles) nodes are such brokers:

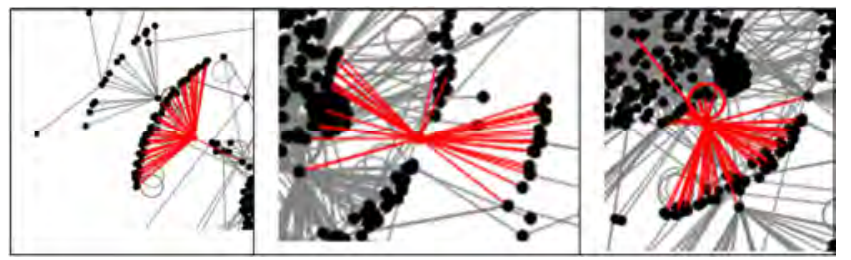

Figure 4. Brokers of information.

We have seen that sorting by vertex 2 and selecting the consecutive records of interest, we were able to obtain the "attention network". If however, we sort by vertex 1 and select the acropolismuseum records again we get the network of outgoing connections ("information network"). This comprises of only 3 tweets, which are actually the three first 
seminal tweets send by @acropolismuseum, the official Twitter account for the museum, on its opening day $(21 / 6 / 2009$ at $16: 26,16: 27$ and 18:54 respectively). These three tweets ("ego") initiated some conversation between "alters" as indicated by the number of retweets/favourites: $13 / 10,9 / 16$ and 12/25 respectively. This suggests a disproportion between the information/attention network activity for the @acropolismuseum ego network. The conversation however, was kept alive by other emerging, active bloggers who engaged in and by means of alternative ways; more specifically hashtags, once the \#acropolismuseum was revealed to the public.

So, our next step was to analyze the network of tweets containing the \#acropolismuseum term. Again, we had to face the problem of case-sensitivity as well as unintended blanks, e.g. \#acropolis museum, which leads to some occurrences of \#acropolis. These may or may not be relevant to the museum, but we chose to filter them out. Applying a custom text filter on hashtags column we found 1230 occurrences, of which 924 were tweets, 30 retweets, 60 replies and 216 mentions:

Custom AutoFilter
Show rows where:
hashtags
Use ? to represent any single character
Use * to represent any series of characters

Figure 5. Filtering hashtags.

The cleaned hashtags network is shown below. Some clusters can also be identified there:

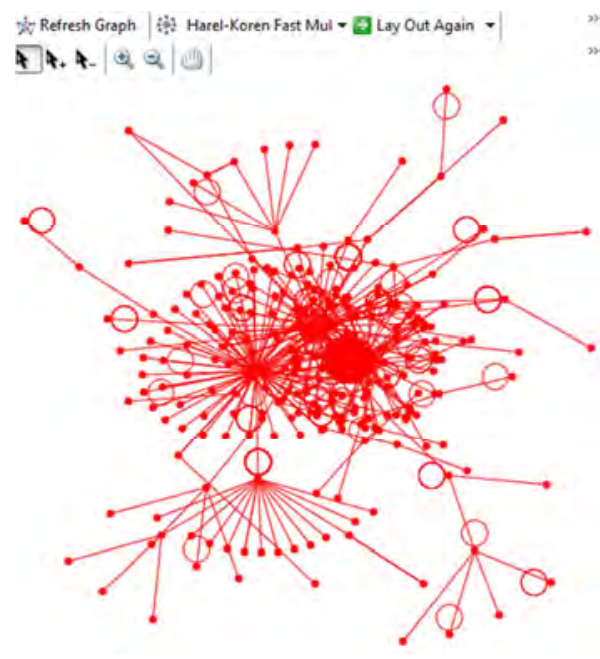

Figure 6. The hashtags network.

Getting a first glimpse (insight) on the hashtags column (where all of the users' hashtags are isolated and listed) shows that some additional topics have emerged in this conversation, igniting other threads: marbles, George Clooney and Amal Alamuddin, travel, architecture, Lego, British museum, instagram, art, sculpture, other museums in Greece, geolocations (Greece, Athens, Plaka), ancient Greece, to name a few.

The order of the hashtags also suggests some patterns on user behavior. As many (possibly naive) users have the habit of including several and occasionally unrelated hashtags, this tends to clutter and distort the thematology of the conversation. Some further processing and analysis of the hashtags network could have been employed at this point, e.g. filtering out reciprocal ties (by de-selecting those with "tweet" as their type), or identifying strong ties (dyads, triads).

Selecting only the tweets according to their type (mention, reply, tweet or retweet) gives the following respective subgraphs, starting from top-left, clockwise:

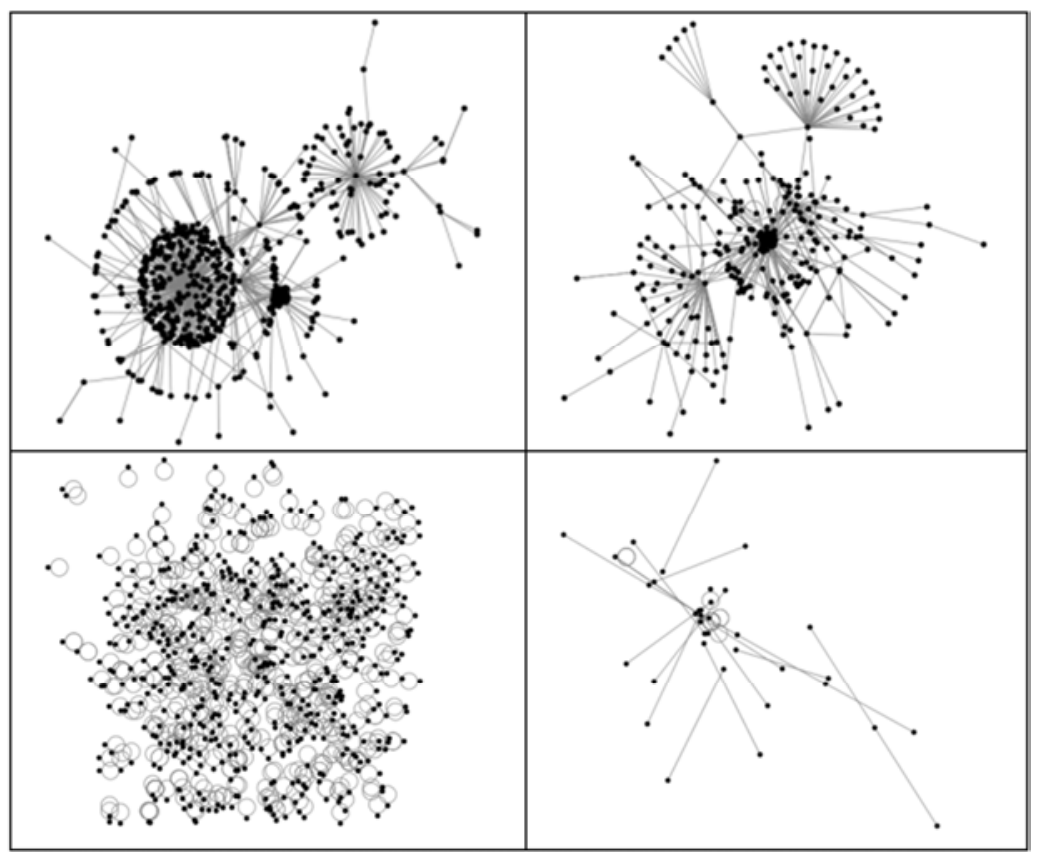

Figure 7. The mention, reply, tweet and retweet networks. 
Once we have a first feel of our dataset, we can proceed with computing various graph metrics. Eigenvector centrality can be used for "attention" by giving the importance of a node (used also in Google's PageRank algorithm) and as a filter against "spamming". On the other hand, betweenness centrality measures the node's position rather than its importance and can be used for "information" - a weighting measure against "redundancy" [33].

Computing the overall graph metrics gives several statistics, shown below (in some cases only the top 10):

Table 2. Top words.

\begin{tabular}{ll}
\hline Top Words in Tweet in Entire Graph & Entire Graph Count \\
\hline Words in Sentiment List\#1: Positive & 1086 \\
Words in Sentiment List\#2: Negative & 209 \\
Non-categorized Words & 34263 \\
Total Words & 35558 \\
acropolismuseum & 2116 \\
com & 1326 \\
twitter & 834 \\
http & 763 \\
pic & 757 \\
\hline
\end{tabular}

Table 3. Top replied-to nodes.

\begin{tabular}{ll}
\hline Top Replied-To in Entire Graph & Entire Graph Count \\
\hline acropolismuseum & 45 \\
stephenfry & 36 \\
bcrpm & 12 \\
elginism & 6 \\
britishmuseum & 5 \\
starwalkersng & 5 \\
corraface & 5 \\
keridouglas & 4 \\
ellymariasymons & 3 \\
archaiologia_en & 3 \\
\hline
\end{tabular}

Table 4. Top mentioned nodes.

\begin{tabular}{|c|c|}
\hline Top Mentioned in Entire Graph & Entire Graph Count \\
\hline acropolismuseum & 801 \\
\hline britishmuseum & 81 \\
\hline acropolis & 72 \\
\hline acropolisathens & 34 \\
\hline visitgreecegr & 31 \\
\hline elginism & 22 \\
\hline 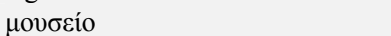 & 15 \\
\hline marblesreunite & 14 \\
\hline bcrpm & 12 \\
\hline nikosaliagas & 12 \\
\hline
\end{tabular}

Table 5. Overall metrics statistics.

\begin{tabular}{ll}
\hline Minimum Degree & 1 \\
Maximum Degree & 331 \\
Average Degree & 2,087 \\
Median Degree & 1,000 \\
Minimum Betweenness Centrality & 0,000 \\
Maximum Betweenness Centrality & 211568,813 \\
Average Betweenness Centrality & 430,687 \\
Median Betweenness Centrality & 0,000 \\
Minimum Closeness Centrality & 0,000 \\
Maximum Closeness Centrality & 1,000 \\
Average Closeness Centrality & 0,137 \\
\hline
\end{tabular}

\begin{tabular}{ll}
\hline Median Closeness Centrality & 0,000 \\
Minimum Eigenvector Centrality & 0,000 \\
Maximum Eigenvector Centrality & 0,050 \\
Average Eigenvector Centrality & 0,001 \\
Median Eigenvector Centrality & 0,000 \\
Minimum PageRank & 0,431 \\
Maximum PageRank & 130,826 \\
Average PageRank & 1,000 \\
Median PageRank & 1,000 \\
Minimum Clustering Coefficient & 0,000 \\
Maximum Clustering Coefficient & 1,000 \\
Average Clustering Coefficient & 0,014 \\
Median Clustering Coefficient & 0,000 \\
\hline
\end{tabular}

Having a look at our network, we noticed a cluster of nodes, the one closest to the bottom. We tried to find a way of filtering it out by means of some of the available metrics, as it seems to consist only of tweets that do not contribute much to the whole conversation. Selecting the ego network of acropolismuseum, sorting by degree (and other metrics) and selecting the top ten nodes still leaves the cluster not participating as seen below (graph only shown for the degree metric):

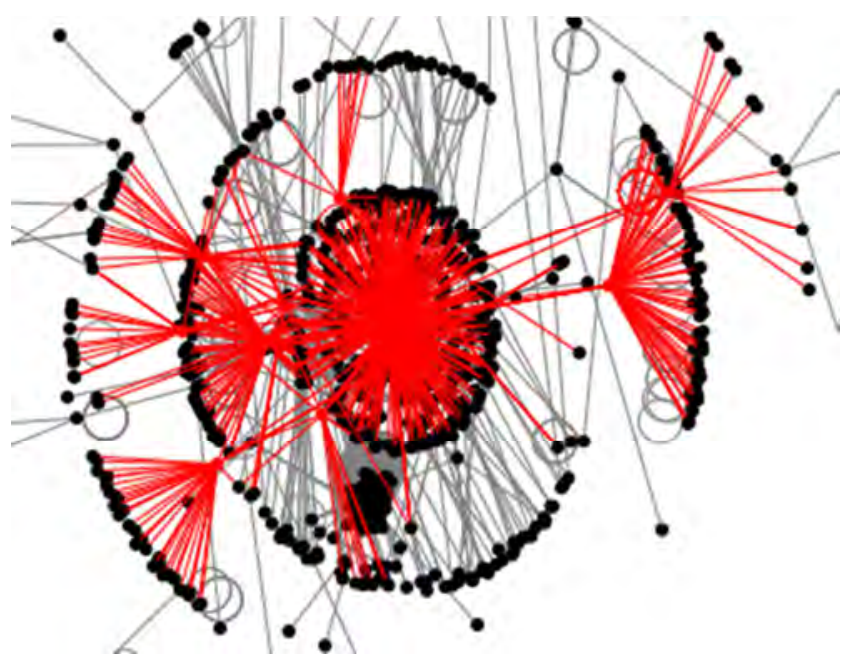

Figure 8.The@acropolismuseum ego network.

The top ten nodes according to different metrics are shown below. There was no success in isolating the "unwanted cluster" using these metrics but are given anyway as they validate the most important nodes.

Table 6. Top ten degree nodes.

\begin{tabular}{ll}
\hline Vertex & Degree (in and out) \\
\hline acropolismuseum & 331 \\
BCRPM & 68 \\
Acropolis & 65 \\
stephenfry & 40 \\
britishmuseum & 30 \\
AcropolisMuseum & 19 \\
MilitaryRaiden & 17 \\
VisitGreecegr & 16 \\
elginism & 14 \\
AcropolisAthens & 12 \\
\hline
\end{tabular}


Table 7. Top ten betweenness centrality nodes.

\begin{tabular}{ll}
\hline Vertex & Betweenness centrality \\
\hline acropolismuseum & 211568,813 \\
BCRPM & 62859,245 \\
Acropolis & 52869,000 \\
JackiePsarianos & 49622,500 \\
stephenfry & 26928,583 \\
britishmuseum & 16106,684 \\
VisitGreecegr & 13897,588 \\
MilitaryRaiden & 12278,000 \\
AcropolisMuseum & 8144,416 \\
elginism & 6681,008 \\
\hline
\end{tabular}

\begin{tabular}{ll}
\hline Vertex & Page Rank \\
\hline elginism & 5,240 \\
ParthenonMarblz & 4,241 \\
\hline
\end{tabular}

However, sorting by closeness centrality and selecting all vertices (174) with this metric equal to 1 (which is the max whereas $\min =0$ ) identifies this cluster which can effectively be neglected.

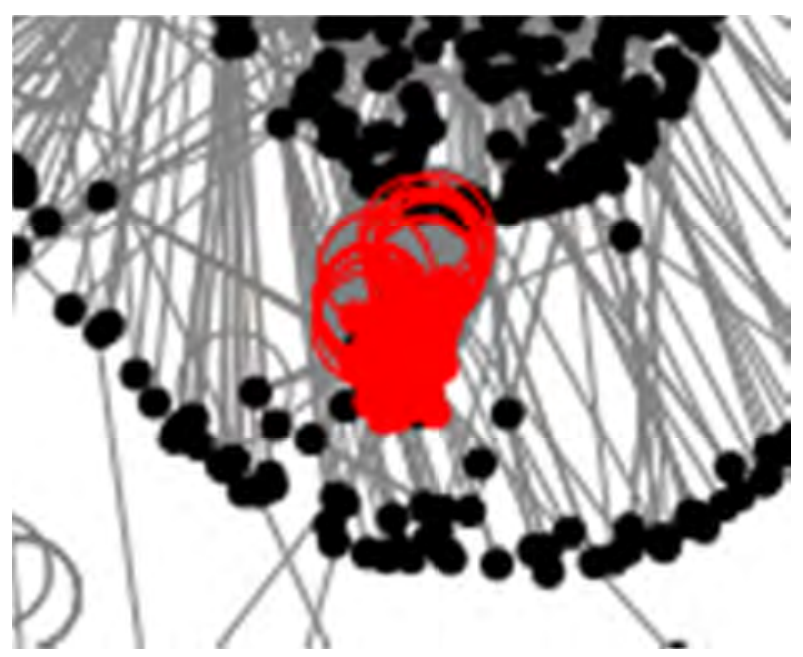

Figure 9. Filtering with closeness centrality.

Better, if sorted by PageRank we can identify that this cluster consists of 619 self-tie nodes that have the PageRank metric equal to exactly 1 ; any other value (meaning they have some other connection as well) gives a node which participates in the rest of the network.

\begin{tabular}{ll}
\hline Vertex & Page Rank \\
\hline acropolismuseum & 130,826 \\
Acropolis & 26,775 \\
BCRPM & 23,545 \\
stephenfry & 17,625 \\
britishmuseum & 11,045 \\
MilitaryRaiden & 7,135 \\
AcropolisMuseum & 6,803 \\
VisitGreecegr & 5,580 \\
\hline
\end{tabular}

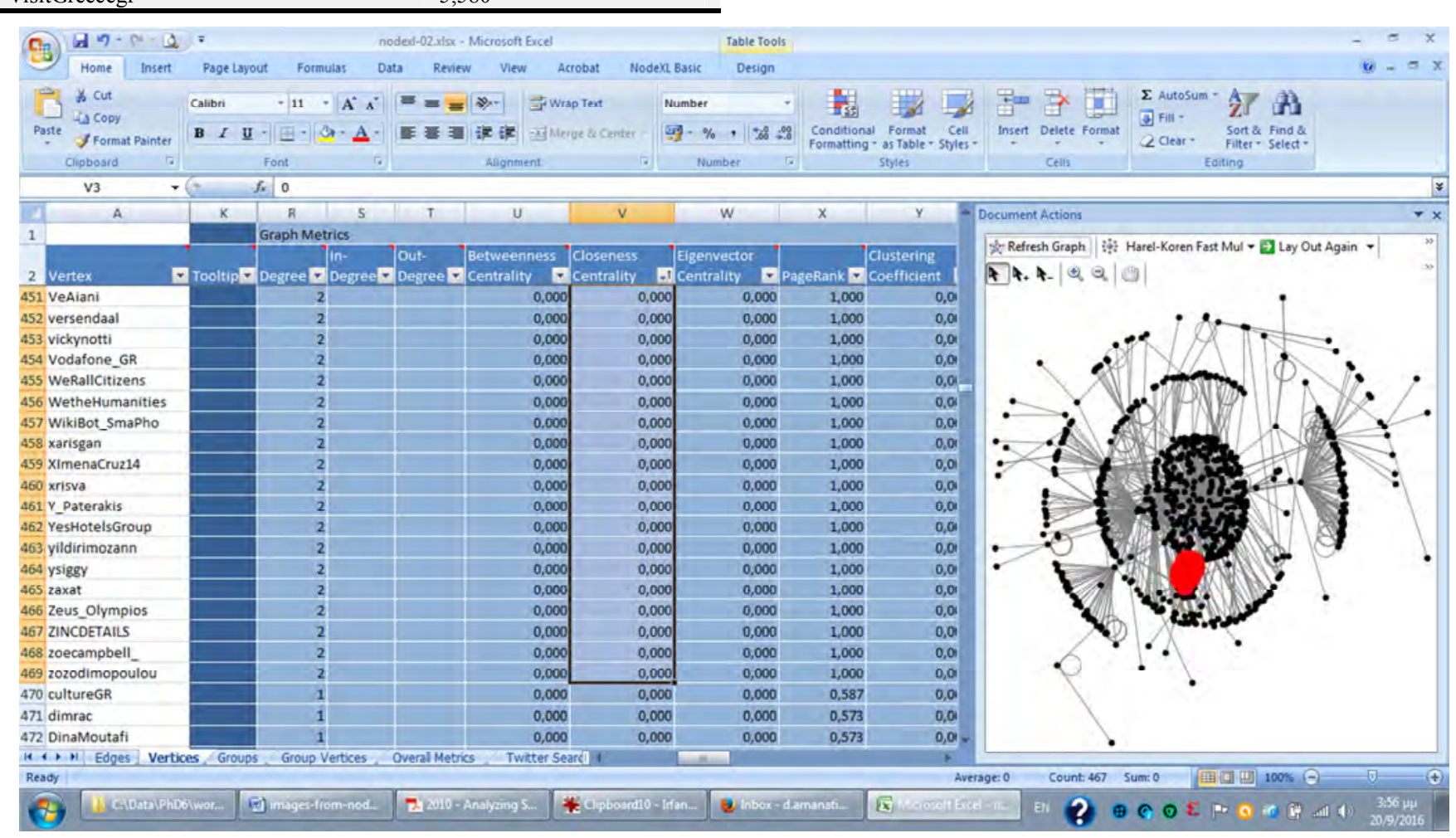

Figure 10. Sorting and selecting by PageRank. 


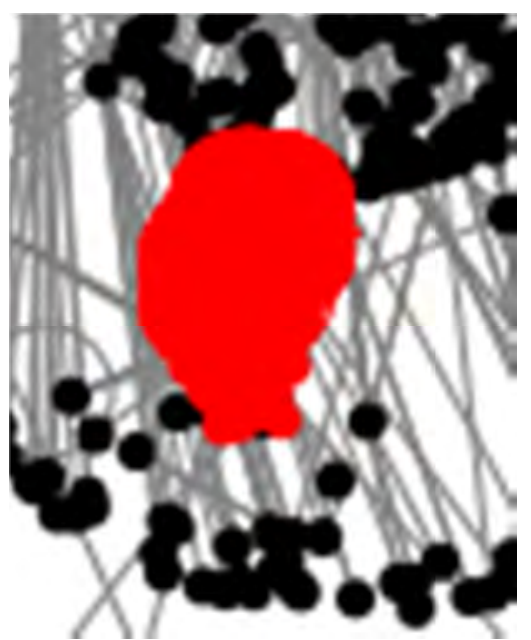

Figure 11. Filtering with PageRank.

For the clustering coefficient, we have only 40 non-zero values. If sorted from largest to smallest and then sorted by PageRank we have to consider some of the zero-valued coefficients which are high in PageRank to reconstruct the network to a large extent (i.e. leaving out only insignificant parts).

\begin{tabular}{|c|c|c|c|c|c|c|c|c|c|c|}
\hline A & $K$ & R & $s$ & $T$ & $u$ & $\mathrm{v}$ & w & $x$ & Y & $z$ \\
\hline & & Graph M & letrics & & & & & & & \\
\hline & & & & out- & |Betweenne & Closeness & Eigenvector & & Clustering & Reciprocated \\
\hline Vertex & Tooltip & Degre- & Des. & Deg? - & $\nabla$ & Centralit: & Centrality & PageRank F & Coefficient II & Vertex Pair Rat: \\
\hline oritishmuseum & & 30 & & & 16106,684 & 0,000 & 0,002 & 11,045 & 0,005 & \\
\hline acropolismuseum & & 331 & & & 211568,813 & 0,001 & 0,050 & 130,826 & 0,001 & \\
\hline Acropolis & & 65 & & & 52869,000 & 0,000 & 0,000 & 26,775 & 0,000 & \\
\hline stephenfry & & 40 & & & 26928,583 & 0,000 & 0,000 & 17,625 & 0,000 & \\
\hline MilitaryRaiden & & 17 & & & 12278,000 & 0,000 & 0,000 & 7,135 & 0,000 & \\
\hline ParthenonMarblz & & 10 & & & 6477,921 & 0,000 & 0,000 & 4,241 & 0,000 & \\
\hline archaiologia_en & & 9 & & & 5498,200 & 0,001 & 0,003 & 3,680 & 0,000 & \\
\hline D_en_i_a & & 5 & & & 10,000 & 0,200 & 0,000 & 2,838 & 0,000 & \\
\hline itarwalkersng & & 5. & & & 10,000 & 0,200 & 0,000 & 2,838 & 0,000 & \\
\hline MarblesReunited & & 8 & & & 4106,447 & 0,001 & 0,003 & 2,452 & 0,000 & \\
\hline ZiteEspace & & 4 & & & 6,000 & 0,250 & 0,000 & 2,378 & 0,000 & \\
\hline NicholsonMuseum & & 5 & & & 3099,500 & 0,000 & 0,000 & 2,127 & 0,000 & \\
\hline Athens & & 4 & & & 2070,000 & 0,000 & 0,000 & 1,990 & 0,000 & \\
\hline The & & 4 & & & 6,000 & 0,250 & 0,000 & 1,931 & 0,000 & \\
\hline sthensplaython & & 3 & & & 3,000 & 0,333 & 0,000 & 1,919 & 0,000 & \\
\hline fgofficial & & 3 & & & 3,000 & 0,333 & 0,000 & 1,919 & 0,000 & \\
\hline cspb & & 4 & & & 2070,000 & 0,001 & 0,003 & 1,898 & 0,000 & \\
\hline ParthenonSuisse & & 4 & & & 2070,000 & 0,001 & 0,003 & 1,898 & 0,000 & \\
\hline zreeknewsagenda & & 6 & & & 2658,522 & 0,000 & 0,000 & 1,881 & 0,000 & \\
\hline ज̆reeceinUSA & & 6 & & & 2563,317 & 0,001 & 0,003 & 1,825 & 0,000 & \\
\hline thinalz & & 3 & & & 5,000 & 0,200 & 0,000 & 1,788 & 0,000 & \\
\hline JreMuseum & & 5 & & & 1381,000 & 0,001 & 0,003 & 1,741 & 0,000 & \\
\hline
\end{tabular}

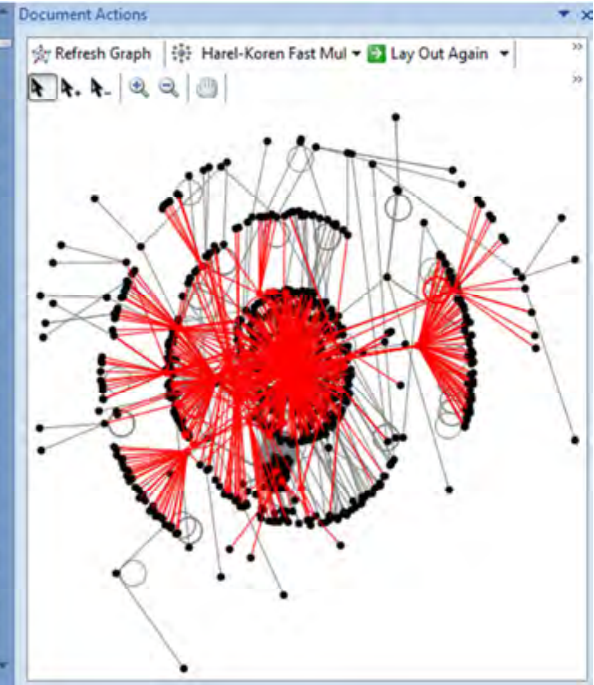

Figure 12. Reconstructing the network.

Thus, our dataset can be processed in various ways within NodeXL, so that e.g., it does not include nodes that do not contribute to the network's conversational structure. However, this can be easily achieved and demonstrated with groups or connected components. First, we need to count and merge duplicate edges. In our case there was only one duplicate (edge weight $\max =2, \min =1)$ :

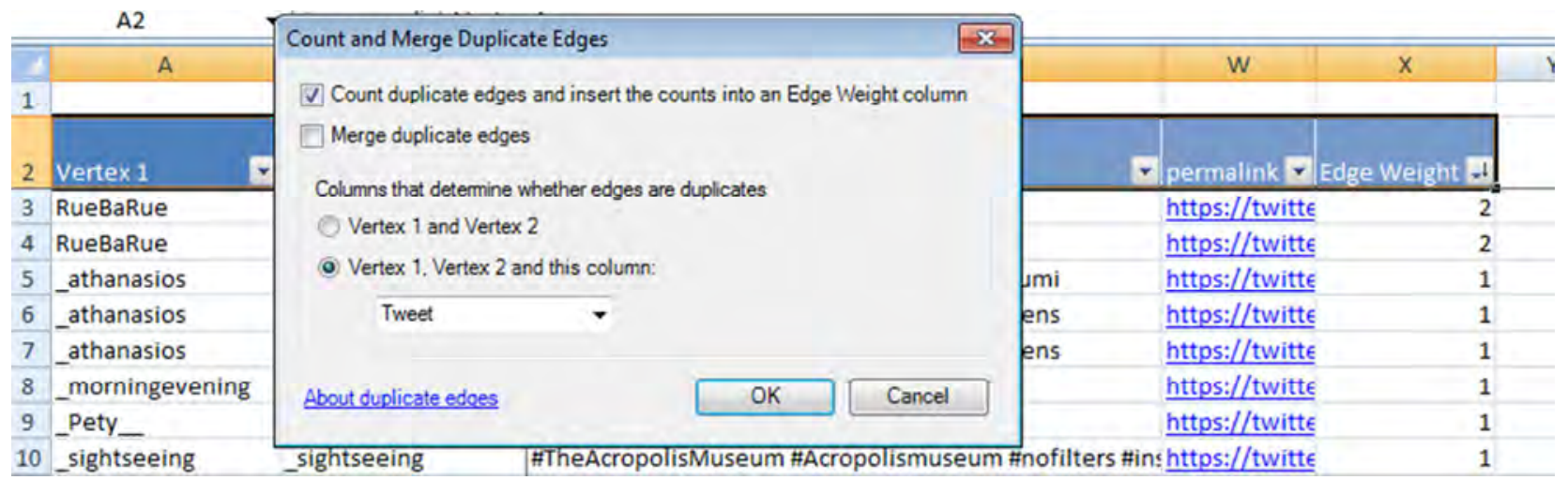

Figure 13. Count and merge duplicate edges. 
Then we can proceed and find clusters (Clauset-NewmanMoore), colour them differently and place isolated nodes in one group:

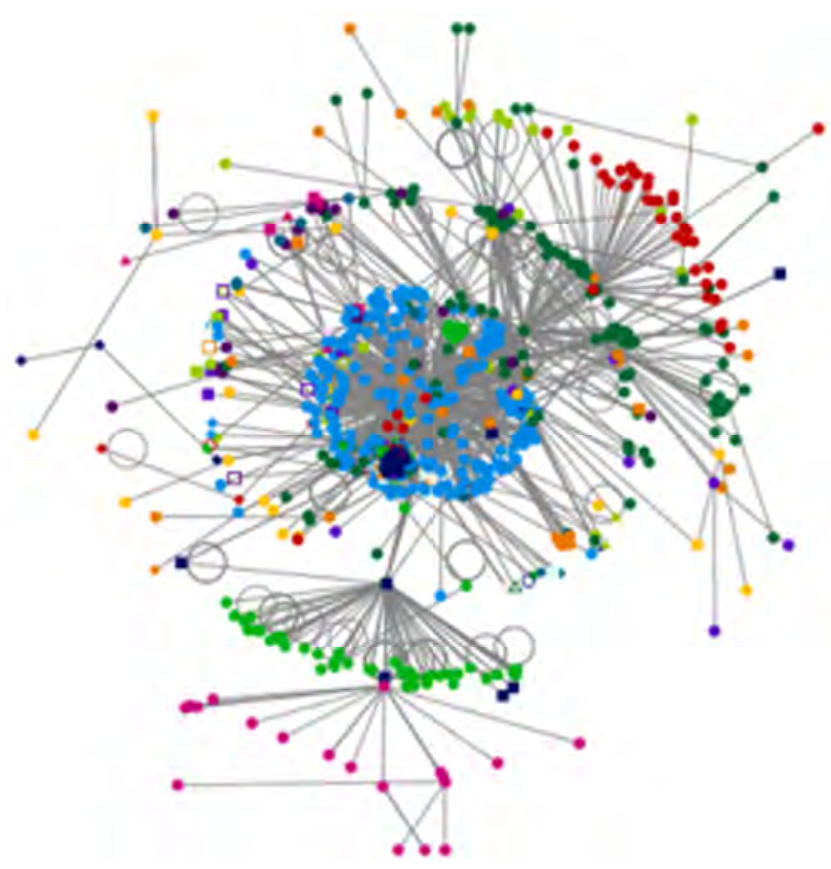

Figure 14. Network clusters.

This creates two new tabs, groups and group vertices. There are 146 groups and some new overall metrics. There are no isolated nodes, groups with only two nodes (dyads) and groups with triads etc. G1 is the previously examined "unwanted" cluster, consisting of reciprocal ties only. Its use is only for hashtags and text (sentiment) analysis, as there is no network, and hence no conversation:

Table 10. Cardinality of each group.

\begin{tabular}{llll}
\hline Group & \# of nodes & Group & \# of nodes \\
\hline G1 & 467 & G10 & 18 \\
G2 & 263 & G11, G12 & 10 \\
G3 & 115 & G13 & 7 \\
G4 & 67 & G14, G15 & 6 \\
G5 & 41 & G16- G19 & 5 \\
G6 & 24 & G20-G25 & 4 \\
G7, G8 & 22 & G26-G45 & 3 \\
G9 & 19 & G46-G146 & 2 \\
\hline
\end{tabular}

On each group, the lowest vertex ID suggests the dominant node in the cluster; e.g. if sorted by vertex id we have (not all displayed):

\begin{tabular}{|l|l|l|l|r|}
\hline & \multicolumn{2}{|c|}{ A } & \multicolumn{2}{c|}{ B } \\
\hline 1 & Group & Vertex & C \\
\hline 2 & G2 & acropolismuseum & 3 \\
\hline 3 & G8 & AcropolisMuseum & 3 \\
\hline 4 & G145 & acropolisMuseum & 3 \\
\hline 5 & G3 & BCRPM & 4 \\
\hline 6 & G4 & Acropolis & 5 \\
\hline 7 & G5 & stephenfry & 6 \\
\hline 8 & G3 & britishmuseum & 7 \\
\hline 9 & G3 & BritishMuseum & 7 \\
\hline 10 & G9 & MilitaryRaiden & 9 \\
\hline 11 & G6 & VisitGreecegr & 10 \\
\hline 12 & G10 & elginism & 11 \\
\hline 13 & G3 & AcropolisAthens & 12 \\
\hline 14 & G6 & ParthenonMarblz & 13 \\
\hline 15 & G7 & archaiologia_en & 14 \\
\hline 16 & G3 & keridouglas & 15 \\
\hline 17 & G10 & MarblesReunited & 16 \\
\hline 18 & G82 & marblesreunited & 16 \\
\hline 19 & G3 & GGWorld & 17 \\
\hline 20 & G3 & KVaselopulos & 18 \\
\hline 21 & G3 & dimitrakarakou & 19 \\
\hline 22 & G18 & ellymariasymons & 20 \\
\hline
\end{tabular}

Figure 15. The groups' dominant nodes.

For a better visualization of the dominant nodes, we could have mapped vertex color to eigenvector centrality and vertex size to betweenness centrality as in [33], but this is not shown here. Other experimentation could have taken place, e.g. grouping by connected components, motif or some vertex attribute.

The subgraph images can be created (default settings) and laid out separately:

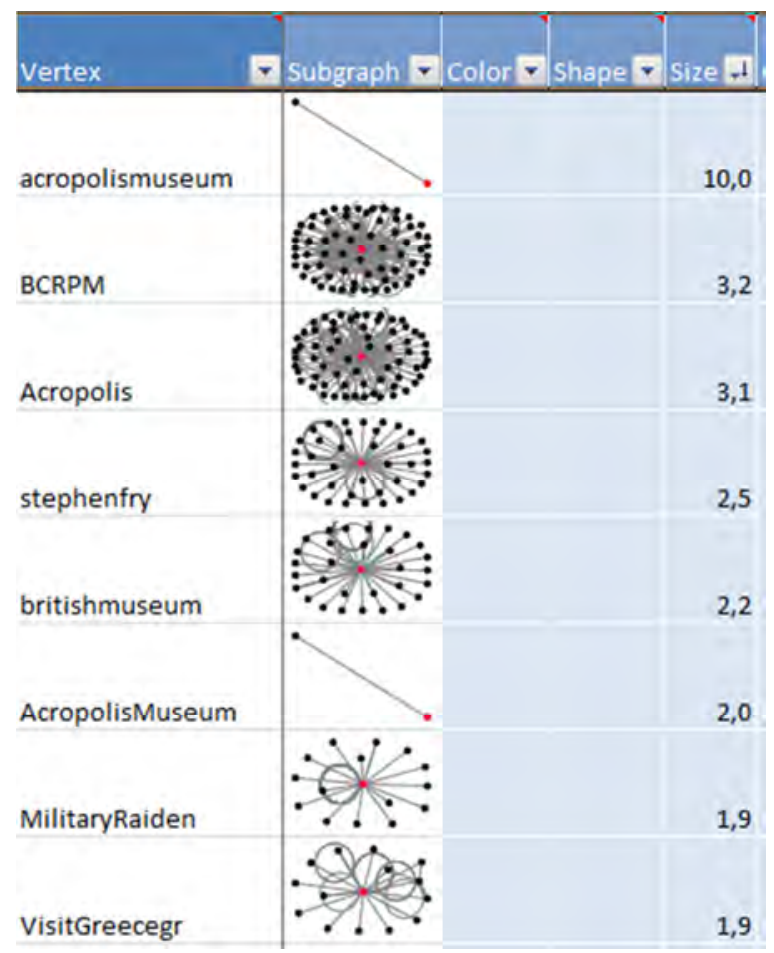

Figure 16. Subgraph thumbnails. 
Our data can be exported in various formats, e.g. GraphML for use in Gephi but this is a NodeXL Pro feature. The tweets' text corpus is also subject to further, more advanced textual analysis, as for example within a word $2 v e c$ model.

\section{Conclusion}

One of the most stunning findings about our network is the disproportion of the "information" and "attention" subnetworks. The former (outgoing connections) comprises of only 3 tweets, which are actually the three first seminal tweets send by @acropolismuseum, the official Twitter account for the museum, on its opening day (21/6/2009 at 16:26, 16:27 and 18:54 respectively). There was no activity since then. On the other hand, bloggers around the world seem to be more passionate about the museum, thereby building the latter network (incoming connections) consisting of replies, retweets, mentions and embedded hashtags.

Most of the tweets in our extracted network about the New Acropolis museum are positive. That means that existing visitors or people that intend to visit the museum have a positive view about it. More than half of the occurrences (almost 1/3) were tweets, while there were very few replies and even fewer retweets. Comparing our study with that of Hausmann we can see that for a popular museum like that of the New Acropolis Museum in Greece, the use of Twitter is significantly lower than in Germany. The same applies when comparing our results with Badell's study where it is obvious that the museum in Spain have more replies than the New Acropolis Museum.

Another finding is that bloggers use other hashtags such as travel, Plaka, Alamuddin and lego. In terms of travel, Athens is a famous destination for a lot of tourists in order to visit the New Acropolis Museum or even the Parthenon. Plaka is the place that the museum is located. Alamuddin a famous lawyer married to George Clooney is a lawyer that makes efforts for the return of Parthenon Marbles. Lego is used as there is an impressive miniature of the Acropolis constructed by Lego in the museum entrance, which was donated by the University of Sydney's Nicholson Museum. Also the Acropolis Museum is organizing educational programs based on Lego. As we can see, hashtags are related to exhibition themes, to locations and to issues about the return of Parthenon Marbles.

Users of social media use Twitter in order to express their opinion, whether positive or negative for the museum. The New Acropolis Museum seems to be the most active museum in Greece that is organizing its communication strategy using social media. The managers of the museum understand that a well organized web-site is not enough for promoting their services and inform future visitors about events and exhibitions. As there is an increase of users of social media they have embodied social media in their "promotion" strategies and they have another way for communication with their public.

\section{References}

[1] Dossis, M., Amanatidis, D., \& Mylona, I. (2015). Mining Twitter Data: Case Studies with Trending Hashtags. Proceedings in ARSA-Advanced Research in Scientific Areas.

[2] McGregor, S. C., \& Mourão, R. R. (2016). Talking Politics on Twitter: Gender, Elections, and Social Networks. Social Media + Society, 2 (3).

[3] Feng, Y. (2016). Are you connected? Evaluating information cascades in online discussion about the \#RaceTogether campaign. Computers in Human Behavior, 54, 43-53.

[4] Bosch, T. (2016). Twitter activism and youth in South Africa: the case of \#RhodesMustFall. Information, Communication \& Society, 1-12.

[5] Yep, J., \& Shulman, J. (2014). Analyzing the library's Twitter network Using NodeXL to visualize impact. College \& Research Libraries News, 75 (4), 177-186.

[6] Smith, M., Shneiderman, B., Milic-Frayling, N., Rodrigues, E. M., Barash, V., Dunne, C., Capone, T., Perer, A. and Gleave, E. (2009). Analysing (Social Media) Networks with Nodexl. Proceedings of the 4th International Conference on Communities and Technologies. Springer, Berlin.

[7] Boyd, D. M., \& Ellison, N. B. (2007). Social network sites: Definition, history, and scholarship. Journal of ComputerMediated Communication, 13, 210-230.

[8] Dabbagh, N., \& Reo, R. (2011). Back to the future: Tracing the roots and learning affordances of social software. In M. J. W. Lee, \& C. McLoughlin (Eds.), Web 2.0-based e-learning: Applying social informatics for tertiary teaching Hershey, PA: IGI Global, pp. 1-20.

[9] Kaplan, A. M., \& Haenlein, M. (2010). Users of the world, unite! The challenges and opportunities of social media. Business Horizons, 53, 59-68.

[10] Schweibenz, W. (2010). Museums and Web 2.0: Some thoughts about authority, communication, participation and trust. In G. Styliaras, D. Koukopoulos, \& F. Lazarinis (eds.), Handbook of research on technologies and cultural heritage: Applications and environments, London: Information Science Reference, 1-15.

[11] Hausmann, A. (2012). Creating buzz opportunities and limitations of social media for arts institutions and their viral marketing, International Journal of Nonprofit and Voluntary Sector Marketing, Int. J. Nonprofit Volunt. Sect. Mark. 7, 173182 .

[12] Romero, D. M., Galuba, W., Asur, S. \& Huberman, B. A. (2010). Influence and Passivity in Social Media. http://papers.ssrn.com/sol3/papers.cfm?abstract_id=165313 (last access 22/12/2016).

[13] Asur S. and Huberman, B. A. (2010) Predicting the Future with Social Media in http://arxiv.org/abs/1003.569 (last access 22/12/2016)

[14] Huberman, B. A., Romero, D. M. and Wu, F. (2009). Social networks that matter: Twitter under the microscope. First Monday, 14 (1). 
[15] Grosseck, G. and Holotescu, C. (2008). Can we use twitter for education activities?. The 4th International Scientific Conference, eLearning and Software for Education. Bucharest, eLSe, April 17-18, 2008.

[16] Kwak, H., Lee, C., Park, H., and Moon, S.(2010). What is Twitter, a social network or a news media? In Proceedings of the 19th International World Wide Web Conference, in http://an.kaist.ac.kr/traces/WWW2010.htm. (last access 12/12/2016).

[17] Bruns A. and Burgess J., (2012). Researching news discussion on Twitter, Journal of Journalism Studies, 13 (5-6).

[18] Kirkpatrick, M., (2011). "There are now $155 \mathrm{~m}$ tweets posted per day, triple the number a year ago" (6 April), at http://readwrite.com/2011/04/06/there_are_now_155m_tweets posted per day triple th, accessed $2 0 / 7 \longdiv { 2 0 1 4 }$.

[19] Twitter: number of active users (2010 - 2016), https://www.statista.com/statistics/282087/number-ofmonthly-active-twitter-users/, last access 30/12/2016.

[20] Messias, J., Schmidt, L., Oliveira, R., and Benevenuto, F. (2013). You followed my bot! transforming robots into influential users in Twitter. First Monday, 18 (7).

[21] Loukaki, A. (2008). Living ruins, value conflicts, Aldershot: Ashgate/coll. Heritage, Culture and Identity.

[22] Ntaflou, C (2011). Poulot, D, Bodenstein, F and Guiral, J M L eds. 'The New Acropolis Museum and the Dynamics of National Museum Development in Greece'. Great Narratives of the Past. Traditions and Revisions in National Museums, Conference proceedings from EuNaMus, European National Museums: Identity Politics, the Uses of the Past and the European Citizen. 29 June - 1 July \& 25-26 November 2011, Paris: 97-111. EuNaMus Report No 4. http://www.ep.liu.se/ecp/078/009/ecp12078009.pdf.

[23] Caskey, M. (2011). Perceptions of the New Acropolis Museum. American Journal of Archaeology Online Museum Review, 115 (3).
[24] Lending, M., (2009). Negotiating absence: Bernard Tschumi's New Acropolis Museum in Athens. The Journal of Architecture, 14: 5, 567-589.

[25] Jakobsen, A. (2012). Experience in-between architecture and context: The New Acropolis Museum, Athens. Journal of Aesthetics \& Culture, 4. Available online in http://www.aestheticsandculture.net/index.php/jac/article/view /18158 (last access 12/12/2016).

[26] Simon, N. (2007). Discourse in the blogosphere: What museums can learn from Web 2.0. Museums \& Social Issues, 2 (2), 257-274.

[27] Kidd, J. (2011). Enacting engagement online: Framing social media use for the museum. Information Technology \& People, 24 (1), 64-77.

[28] Lovejoy K. and Gregory D. Saxton, G. D. (2012). Information, Community, and Action: How Nonprofit Organizations Use Social Media. Journal of ComputerMediated Communication, 17, 337-353.

[29] NRW-Forum Dusseldorf - Twitter, http://twitter.com/\#!/nrw_forum, (last access on 30/12/2016).

[30] De Gottardo, F. (2014). Social media in the museum field (Research report). Smithsonian Institution Traveling Exhibition Service. in http://www.svegliamuseo.com/wpcontent/uploads/2014/09/Social-Media-in-the-MuseumField_FrancescaDeGottardo.pdf, (last access, 20/12/2016).

[31] Badell, J, I, (2015). Museums and social media: Catalonia as a case study. Journal Museum Management and Curatorship 30 (3), 244-263.

[32] Granovetter, M. S. 1973. The strength of weak ties. American Journal of Sociology, 78: 1360-1380.

[33] Hansen, D., Shneiderman, B., \& Smith, M. A. (2010). Analyzing Social Media Networks with NodeXL: Insights from a Connected World. Boston, MA: Morgan Kaufmann. 